\title{
Performance of IEEE 802.14.5 and ZigBee protocol on realtime monitoring augmented reality based wireless sensor network system
}

\author{
Arda Surya Editya ${ }^{1, *}$, Surya Sumpeno ${ }^{2}$, Istas Pratomo ${ }^{3}$ \\ Sepuluh Nopember Institute of Technology, Surabaya, Indonesia \\ Iardasurya@gmail.com*; ${ }^{2}$ surya@ee.its.ac.id; ${ }^{3}$ istaspra@ee.its.ac.id \\ * corresponding author
}

Article history:

Received August 7, 2017

Revised August 16, 2017

Accepted August 21, 2017

Keywords:

Augmented Reality

Wireless Sensor Network

ZigBee Protocol

IEEE 802.14.5

Real-time Monitoring
The internet of Thing (IoT) technology has much development in this era. It has various wireless media transmission systems such as ESP and Xbee. Some IoT device can monitor website or application. On the other hand, Augmented Reality (AR) is a technology that used more on the entertainment sector. Here, we try to use AR to monitor the Xbee based IoT device. As a result, there is the different result between ZigBee Protocol and IEEE 802.14.5 real time monitoring system. The optimum estimation of real-time time tolerance of those monitoring systems is $>1500 \mathrm{~ms}$ (IEEE 804.14.5) and $>50 \mathrm{~ms}$ (ZigBee protocol).

Copyright $(9) 2017$ International Journal of Advances in Intelligent Informatics. All rights reserved.

\section{Introduction}

Communication technology is increasingly developed in this era. Many technologies are invented to make data transfer faster at the same times with powerless [1]-[3]. Communication technology become important because every sensor in each device must transfer data to other devices.

A smart sensor device must support wireless communication, sensor, and computation. A smart wireless sensor device commonly has the a microcontroller which has computation function, a small RAM for dynamic data function, a wireless transceiver, many flash memories which hold the code of program and long-lived data, an analog-to-digital converter (ADC), an antenna, many sensors, and a source of power. Most Wireless Sensor Network (WSN) are rely on a communications stack that which including a medium access control (MAC), multihop networks, transport layers, and routing [2]. Each layer has many protocols, but they are not similar with protocols which found in even WiFi networks or wired networks. In communication, WSN have a communication protocol. Most popular protocol used in wireless sensor network is IEEE 802.14.5 and ZigBee Protocol. The specification of IEEE 802.15.4 describes wireless and media access protocols for personal area networking devices [4]. Each performance of protocol had been described by Timmons and Scanlon [5], the performance of IEEE 802.15.4 for Medical Sensor Body Area Networking have same problem. Therefore research is needed to solve the problem through simulation. Lopez et.al. [6] describe ZigBee protocol performance in medical body sensor with simulation that have some weakness namely when it delay will increase data loss. Zhang [7] has used the Time Division Cluster Schedule (TDCS) on WSN as a periodic scheduling for avoiding the collision flow while meeting the end-to-end delay deadlines.

Wireless technology is known to make data transfer more efficient and easy but it takes more power. Nowadays the wireless technology has use less power than normal [3], [8]. This low power wireless technology is produced by Digi Enterprise with their product named Xbee [9]-[11]. Xbee have two versions S1 with IEEE 802.15.4 and other with ZigBee Protocol. Many devices built with wireless sensor network [1], [3], [8], [12], [13], but there is some problem found because device that built by Xbee must be combined by external devices like Arduino or Micro-controller to maximize the device performance [9]-[11], [14]. 
This research is purposed to solve the problem that arises when Xbee with protocol IEEE 802.15.4 and ZigBee protocol tried to send data sensor in real-time manner. The problem arises after error appeared after take some ADC sampling the value of data sensor and back to normal after that. Also, the sensor data values, which sent to the receiver, has not same with the original data sensor, which take in Arduino serial and even make the data sensor give the wrong value to receiver. This trouble is important because in real-time monitoring system, it is not allowed to have an error while sensor data taken. The researcher will use map method to reconfigure ADC value that could be found on Arduino to solve this problem.

\section{Related Works}

The use of sensor device is applied to the monitoring system to monitor something. Monitoring systems in some Industries and agriculture sectors need to be reviewed and monitored. Usually monitoring system use an LCD that embedded in the machine, but at the other, the use of website to monitor sensor in device monitoring system has been able. As seen in Fig.1, nowadays monitoring system can be used for augmented reality technology. Goldsmith et.al. [15] explain that wireless sensor network can be used on environmental monitoring system.

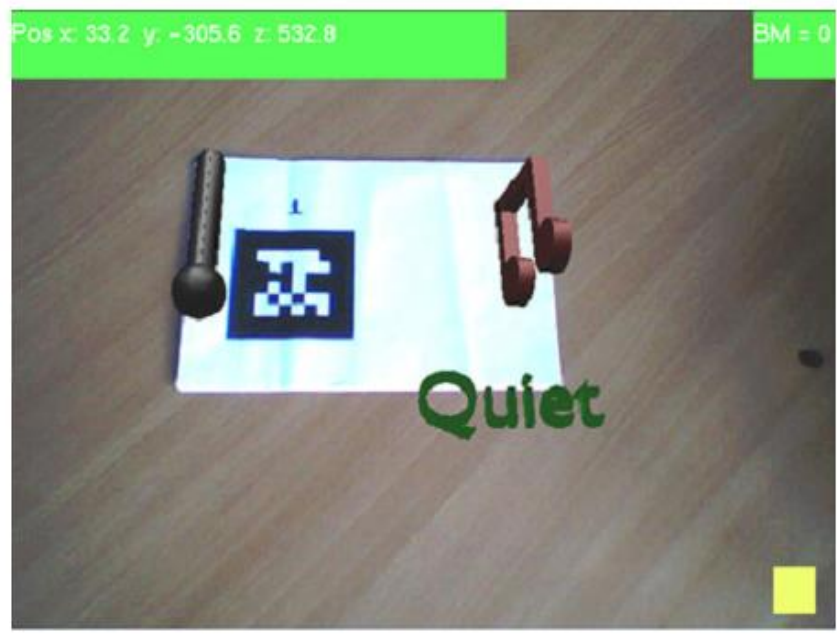

Fig. 1. Augmented Reality for environmental monitoring using WSN

Pokric et. al. [16] proved that Augmented Reality can be implemented for Internet of things (IoT) Services. The results show that Augmented Reality can be used for gaming. One example is shown in Fig.2.

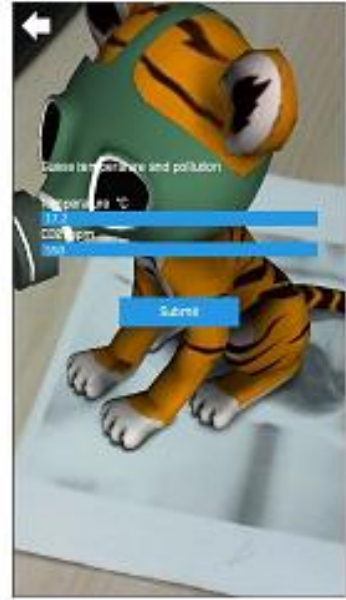

(a)

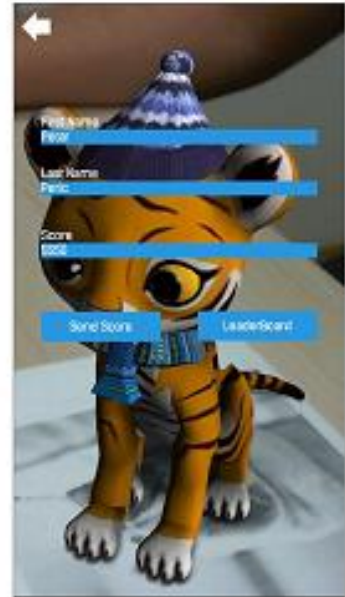

(b)

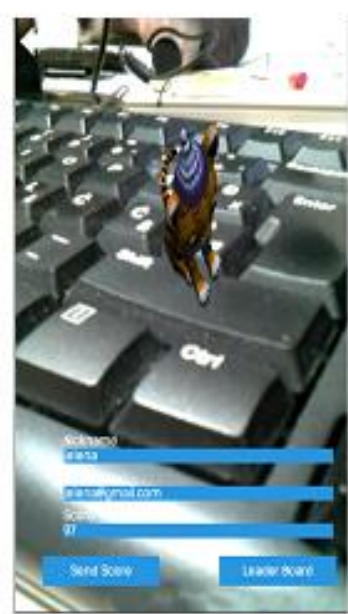

(c)

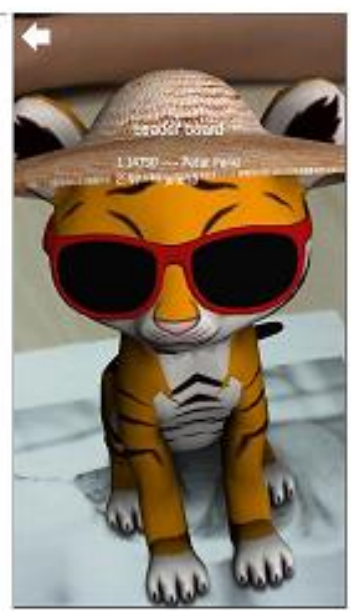

(d)

Fig. 2. Augmented Reality Enabled IoT services for gaming 
In the future, monitoring data technology is very important besides transmission media. There are more technologies can monitor much data as using web pages, the Android application or using augmented reality [17]-[20]. Augmented reality is a technology that will bring digital content to real world using camera and latches called marker. Many developments have been done to make augmented reality easy to use and maximize to work [19]. Nowadays, there are many AR glasses which were known in the market like Hololens by Microsoft, and META by meta corp [17]. This is a sign which means augmented reality will be implemented in a various sector in the future including IoT technology [18], [21]. For now, there are many research conducted to improve augmented reality in IoTs.

Huan et. al. [22] has been designed and implemented augmented reality as a space robot telescope which is very effective so the user can see the robot movement which is depicted with augmented reality object, so it is easy to control long distance. Pan et. al. [23] made an augmented reality system to monitor the efficiency of electronic devices. Gandhi [24] made an augmented reality system that used to monitor fire victims by pointing to the location of the victim. Lee et. al. [21] using Augmented Reality to teach kindergarten students English vocabulary. Chaczko et. al. [18] using Augmented Reality to monitor Remote-Lab. The project shows how Augmented Reality utilized with overlay Smart-Grid can support the learning process in attractive methods for monitoring events of captured scenes in remote-lab such as video stream, Web-link from smart devices' camera. Gaffary et. al. [17] have been designed an experimental setup based on a Microsoft HoloLens and a haptic force-feedback device. They are enabling them for pressing a virtual piston, and make stiffness successively comparation with either Augmented Reality.

\section{System Design}

This work will use two protocol that embedded on two kinds of Xbee. First is Xbee S1 that using IEEE 802.14.5 Protocol communication and Xbee S2 that using ZigBee Protocol communication. This system is divided by two devices, first is transmitter (Fig.3) that connected with three sensors: Soil Moisture, Humidity and LDR sensors. Transmitter will transmit three types of sensor data through each protocol IEEE 802.15.4 and ZigBee protocol and receive by the receiver that built by WSN and Arduino which connected to database. Data from database will be continued and displayed in Augmented Reality Object through mobile device (smartphone).

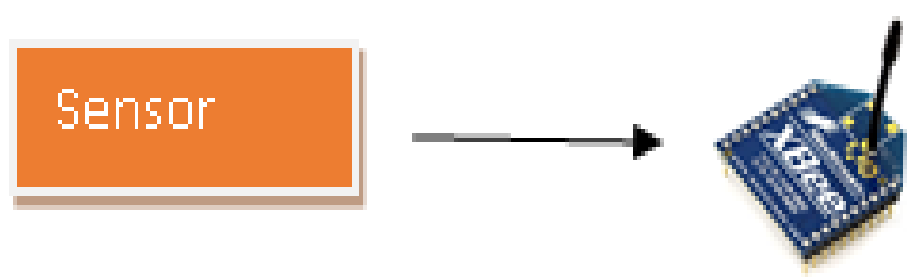

Fig. 3. Transmitter design.

We have two system designs, first is the use as transmitter design, the sensor will transmit the value to Xbee (WSN) and the data sensor will be forwarded to receiver. Second, the receiver system (Fig. 4) that will receive any information from transmitter start from Xbee (WSN) and the data will be carried forward to Arduino and proceeded to take a serial data from WSN protocol and forwarded to database. Afterwards, the phone with Augmented Reality Monitoring System will display the data (Fig.5). 

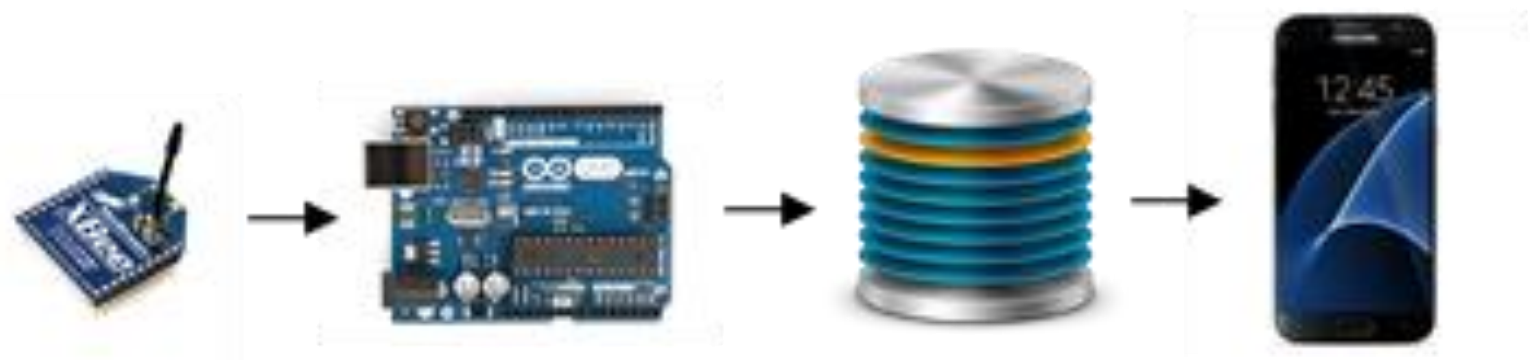

Fig. 4. Receiver design.

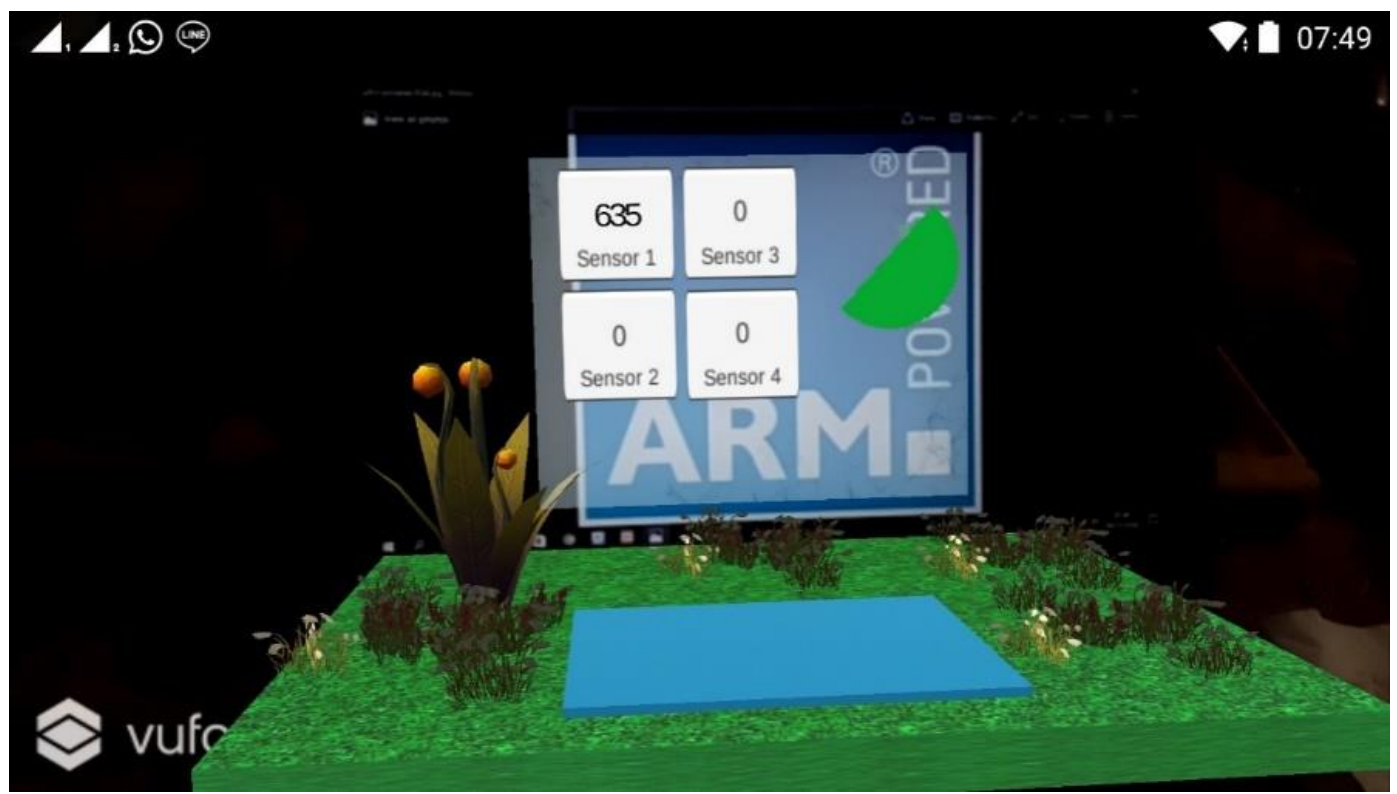

Fig. 5. Augmented Reality Apps

\section{Experimental Result}

The experiment will test the performance of IEEE 802.14.5 and ZigBee protocol in Augmented Reality Monitoring system. Some factors which is considered on the performance measurements as follows:

\section{1) IO Sampling Rate}

In the first test scenario, it will take the total Packet Error Rate that occurs during system testing where the system tested. Each system will be tested for four times with different sampling rate IO. Table 1 shows the Measurement Table Packet Error Rate IEEE 802.14.5 Protocol. Table 2 shows the same measurement for ZigBee.

Table 1. Measurement of packet error rate IEEE 802.14.5 Protocol

\begin{tabular}{|c|c|c|c|c|c|c|c|}
\hline \multirow[t]{2}{*}{ No } & \multirow{2}{*}{$\begin{array}{c}\text { Io Sampling } \\
\text { Rate }\end{array}$} & \multicolumn{2}{|c|}{$\begin{array}{c}\text { Packet Error Rate } \\
\text { (Node - Coordinator) }\end{array}$} & \multirow[t]{2}{*}{ Throughput } & \multicolumn{2}{|c|}{$\begin{array}{l}\text { Packet Error Rate } \\
\text { (Node - Database) }\end{array}$} & \multirow[t]{2}{*}{ Throughput } \\
\hline & & Node 1 & Node 2 & & Node 1 & Node 2 & \\
\hline 1 & $50 \mathrm{~ms}$ & $78 \%$ & $76 \%$ & 820 bps & $76,5 \%$ & $78,5 \%$ & 697 bps \\
\hline 2 & $100 \mathrm{~ms}$ & $20,3 \%$ & $21,4 \%$ & $410 \mathrm{bps}$ & $52,3 \%$ & $50,5 \%$ & $328 \mathrm{bps}$ \\
\hline 3 & $500 \mathrm{~ms}$ & $0 \%$ & $0 \%$ & $82 \mathrm{bps}$ & $3 \%$ & $2 \%$ & $82 \mathrm{bps}$ \\
\hline 4 & $1000 \mathrm{~ms}$ & $0 \%$ & $0 \%$ & $41 \mathrm{bps}$ & $0 \%$ & $0 \%$ & $41 \mathrm{bps}$ \\
\hline
\end{tabular}


From the Table 1 and 2 can be concluded that smaller IO sampling rate will increase Packet Error because of the Arduino coordinator decode the packet and then it takes time to decode so that the Xbee $\mathrm{S} 1$ has a limited sampling rate capability due to the power used on Xbee S1 is also limited i.e. only 3.3V. Also, Packet Error Rate generated by the ZigBee protocol is almost below than 3\%, because the ZigBee protocol has been improved in the protocol. This can be seen with the reference voltage that cannot be changed as well as the function of the ZigBee protocol which have bigger than IEEE 802.14.5 protocol. The result shows that ZigBee protocol is better in sending data, this is proved by the number of packet error which less than when use IEEE 802.14.5 protocol.

Table 2. Measurement Table Packet Error Rate ZigBee Protocol

\begin{tabular}{cccccccc}
\hline No & $\begin{array}{c}\text { Io Sampling } \\
\text { Rate }\end{array}$ & $\begin{array}{c}\text { Packet Error Rate } \\
\text { (Node - Coordinator) }\end{array}$ & Throughput & \multicolumn{2}{c}{$\begin{array}{c}\text { Packet Error Rate } \\
\text { (Node - Database) }\end{array}$} & Throughput \\
\cline { 3 - 5 } & Node 1 & Node 2 & & Node 1 & Node 2 & \\
\hline 1 & $50 \mathrm{~ms}$ & $0 \%$ & $0 \%$ & $820 \mathrm{bps}$ & $0 \%$ & $0 \%$ & $697 \mathrm{bps}$ \\
2 & $100 \mathrm{~ms}$ & $0 \%$ & $0 \%$ & $410 \mathrm{bps}$ & $2 \%$ & $2 \%$ & $328 \mathrm{bps}$ \\
3 & $500 \mathrm{~ms}$ & $0 \%$ & $0 \%$ & $82 \mathrm{bps}$ & $1 \%$ & $1 \%$ & $82 \mathrm{bps}$ \\
4 & $1000 \mathrm{~ms}$ & $0 \%$ & $0 \%$ & $41 \mathrm{bps}$ & $0 \%$ & $0 \%$ & $41 \mathrm{bps}$ \\
\hline
\end{tabular}

2) Sensor Quantity

In this study, the influence of the number of sensors will be tested against the Packet Error Rate both on the IEEE 802.14.5 and ZigBee protocols. Table 3 and 4 shows the sensor quantity measurement for IEE protocol and ZigBee.

Table 3. Measurement Table Packet Error Rate IEEE 802.14.5

\begin{tabular}{cccccccccc}
\hline \multirow{2}{*}{ No } & $\begin{array}{c}\text { Jumlah } \\
\text { Sensor }\end{array}$ & \multicolumn{3}{c}{$\begin{array}{c}\text { Packet Error Rate } \\
\text { (Node - Coordinator) }\end{array}$} & \multicolumn{3}{c}{$\begin{array}{c}\text { Packet Error Rate } \\
\text { (Node - Database) }\end{array}$} \\
\cline { 3 - 11 } & $\mathbf{5 0} \mathbf{m s}$ & $\mathbf{1 0 0} \mathbf{m s}$ & $\mathbf{5 0 0} \mathbf{~} \mathbf{s}$ & $\mathbf{1 0 0 0} \mathbf{~} \mathbf{s}$ & $\mathbf{5 0 ~} \mathbf{m s}$ & $\mathbf{1 0 0} \mathbf{m s}$ & $\mathbf{5 0 0} \mathbf{m s}$ & $\mathbf{1 0 0 0} \mathbf{~ m s}$ \\
\hline 1 & 1 Sensor & $78 \%$ & $20,3 \%$ & $0 \%$ & $0 \%$ & $76,5 \%$ & $52,3 \%$ & $3 \%$ & $0 \%$ \\
2 & 2 Sensor & $78,5 \%$ & $20 \%$ & $1 \%$ & $0 \%$ & $78 \%$ & $35,4 \%$ & $3 \%$ & $0 \%$ \\
3 & 3 Sensor & $80 \%$ & $23 \%$ & $1 \%$ & $1 \%$ & $80 \%$ & $36,4 \%$ & $3 \%$ & $1 \%$ \\
4 & 4 Sensor & $82 \%$ & $25 \%$ & $1 \%$ & $1 \%$ & $85 \%$ & $37 \%$ & $3 \%$ & $2 \%$ \\
\hline
\end{tabular}

Table 4. Measurement Table Packet Error Rate ZigBee

\begin{tabular}{|c|c|c|c|c|c|c|c|c|c|}
\hline \multirow{2}{*}{ No } & \multirow{2}{*}{$\begin{array}{l}\text { Jumlah } \\
\text { Sensor }\end{array}$} & \multicolumn{4}{|c|}{$\begin{array}{c}\text { Packet Error Rate } \\
\text { (Node - Coordinator) }\end{array}$} & \multicolumn{4}{|c|}{$\begin{array}{l}\text { Packet Error Rate } \\
\text { (Node - Database) }\end{array}$} \\
\hline & & $50 \mathrm{~ms}$ & $100 \mathrm{~ms}$ & $500 \mathrm{~ms}$ & $1000 \mathrm{~ms}$ & $50 \mathrm{~ms}$ & $100 \mathrm{~ms}$ & $500 \mathrm{~ms}$ & $1000 \mathrm{~ms}$ \\
\hline 1 & 1 Sensor & $0 \%$ & $0 \%$ & $1 \%$ & $0 \%$ & $0 \%$ & $2 \%$ & $1 \%$ & $0 \%$ \\
\hline 2 & 2 Sensor & $0 \%$ & $0 \%$ & $1 \%$ & $0 \%$ & $0 \%$ & $2 \%$ & $1 \%$ & $0 \%$ \\
\hline 3 & 3 Sensor & $1 \%$ & $1 \%$ & $1 \%$ & $0 \%$ & $1 \%$ & $2 \%$ & $2 \%$ & $0 \%$ \\
\hline 4 & 4 Sensor & $1 \%$ & $1 \%$ & $1 \%$ & $0 \%$ & $1 \%$ & $2 \%$ & $2 \%$ & $0 \%$ \\
\hline
\end{tabular}


From the comparison of Table 3 and Table 4 can be concluded that after added more number of sensors to the WSN, the packet error rate will be increased. This is due to the amount of large data transferred, the limited power and also the processor used in wireless sensor network, which resulting number of packet error rate. However, the packet error rate that occurs does not exceed the $1 \%$ threshold of point to point communication and not more than $2 \%$ for the communication node to the database. This proved that the ZigBee protocol of data transmission has a lot of improvements so that the packet error rate declined even though the number of sensors added up to 4 sensors.

\section{3) Distance}

In this test, we will test the influence of distance to Packet Error Rate both on IEEE 802.14.5 and ZigBee protocol. In this test IO Sampling Rate $1000 \mathrm{~ms}$ will be used. Here is a table of relationships between Packet Error Rate of IEEE 802.14.5 and ZigBee protocols. Fig.6 shows the measurement of the effect of distance to the packet error rate under Line of Sight (LOS) conditions.

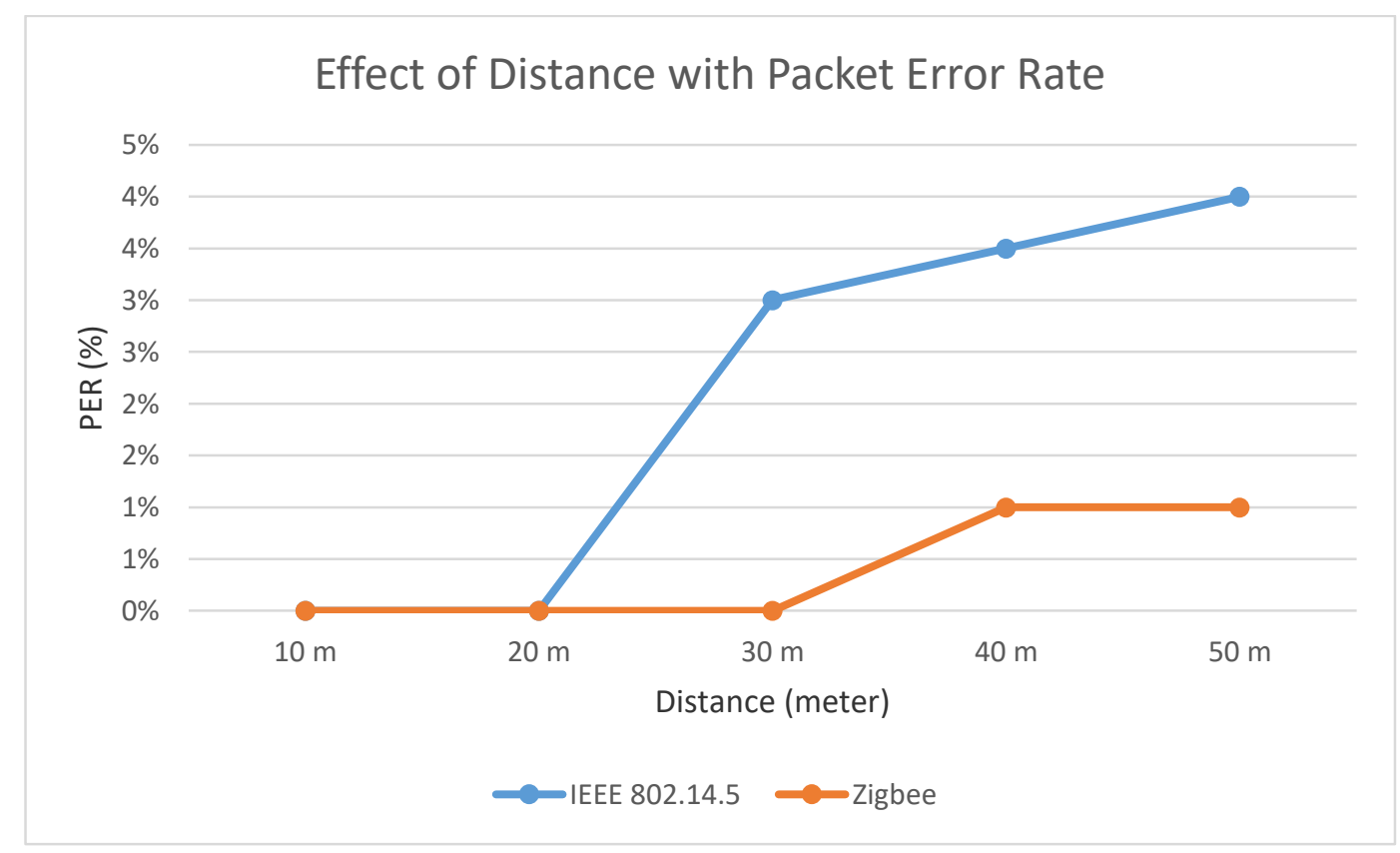

Fig. 6. Correlation between distance and packet error rate

Based on Fig 6, the packet error rate level of these two protocols is different from the IEEE 802.14.5 protocol which has many packet error rates compared to the ZigBee protocol. This is possible because the ZigBee protocol has many improvements compared to the IEEE 802.14.5 protocol.

\section{Conclusion}

In this paper, we have encountered problem which is each protocol had a minimum time to do IO sampling rate. As we can see on protocol IEEE 802.14.5, It had minimum time to take IO sampling rate without wrong value in $1500 \mathrm{~ms}$, and ZigBee protocol had minimum time to do IO sampling rate without wrong value in $50 \mathrm{~ms}$. Therefore, ZigBee protocol is the better protocol to be used in Augmented Reality monitoring system because it has minimum time to take a sampling data with correct value. In future work, the research will be focused on measuring more factors to make realtime augmented reality monitoring system by using a total sensor on the system using routing protocol, and improving efficiency of power usage. The future research may give more contribution on the WSN based monitoring system.

\section{References}

[1] F. Chen, L. Qin, X. Li, G. Wu, and C. Shi, "Design and Implementation of ZigBee Wireless Sensor and Control Network System in Greenhouse," in Proceedings of the 36th Chinese Control Conference, Dalian, China, 2017. 
[2] M. C. B. Gragasin, M. P. A. Talplacido, and N. A. Macabale Jr, "Throughput Evaluation of Raspberry Pi Devices on Multihop and Multiflow Wireless Sensor Network Scenarios," in International Conference on Signals and Systems (ICSigSys), 2017.

[3] K. Zheng et al., "Energy-Efficient Localization and Tracking of Mobile Devices in Wireless Sensor Networks," IEEE Trans. Veh. Technol., vol. 66, no. 3, pp. 2714-2726, Mar. 2017.

[4] H. Li, B. Xue, and W. Song, "Application and analysis of IEEE 802.14.5 security services," in 2010 International Conference on Networking and Digital Society, 2010, vol. 2, pp. 139-142.

[5] N. F. Timmons and W. G. Scanlon, "Analysis of the performance of IEEE 802.15. 4 for medical sensor body area networking," in Sensor and ad hoc communications and networks, 2004. IEEE SECON 2004. 2004 First Annual IEEE Communications Society Conference on, 2004, pp. 16-24.

[6] H. Fernández-López, P. Macedo, J. A. Afonso, J. H. Correia, and R. Simões, "Performance evaluation of a ZigBee-based medical sensor network," in Pervasive Computing Technologies for Healthcare, 2009. PervasiveHealth 2009. 3rd International Conference on, 2009, pp. 1-4.

[7] Z. Zhang, "IEEE 802.14. 5/ZigBee Based WSNs--WPANs and Innovative Application in Medical Health Care Systems," Innov. Med. Healthc. 2014, vol. 207, p. 125, 2015.

[8] C. A. Ramírez, R. C. Barragán, G. García-Torales, and V. M. Larios, "Low-power device for wireless sensor network for Smart Cities," in Microwave Conference (LAMC), IEEE MTT-S Latin America, 2016, pp. 1-3.

[9] Y. F. Solahuddin and W. Ismail, "Data fusion for reducing power consumption in Arduino-Xbee wireless sensor network platform," in Computer and Information Sciences (ICCOINS), 2014 International Conference on, 2014, pp. 1-6.

[10] H. Kumbhar, "Wireless sensor network using Xbee on Arduino Platform: An experimental study," in Computing Communication Control and automation (ICCUBEA), 2016 International Conference on, 2016, pp. 1-5.

[11] N. S. A. Zulkifli, F. C. Harun, and N. S. Azahar, "XBee wireless sensor networks for Heart Rate Monitoring in sport training," in Biomedical Engineering (ICoBE), 2012 International Conference on, 2012, pp. 441-444.

[12] Y.-J. Pan and H.-T. Nian, "The development of microsystems device based on Wireless Sensor Network," in Computer Communication Control and Automation (3CA), 2010 International Symposium on, 2010, vol. 1, pp. 419-422.

[13] A. Samuel and K. Karyono, "ZLeAp: Application for wireless sensor network (ZigBee) learning tool," in New Media (CONMEDIA), 2015 3rd International Conference on, 2015, pp. 1-5.

[14] S. G. Nikhade and A. A. Agashe, "Wireless Sensor Network Communication Terminal Based on Embedded Linux and Xbee," in International Conference on Circuit, Power and Computing Technologies [ICCPCT], 2014.

[15] D. Goldsmith, F. Liarokapis, G. Malone, and J. Kemp, "Augmented reality environmental monitoring using wireless sensor networks," in Information Visualisation, 2008. IV'08. 12th International Conference, 2008, pp. 539-544.

[16] B. Pokric et al., "Augmented Reality Enabled IoT Services for Environmental Monitoring Utilising Serious Gaming Concept.," JoWUA, vol. 6, no. 1, pp. 37-55, 2015.

[17] Y. Gaffary, B. Le Gouis, M. Marchal, F. Argelaguet, B. Arnaldi, and A. Lecuyer, “AR Feels 'Softer' than VR: Haptic Perception of Stiffness in Augmented versus Virtual Reality," IEEE Trans. Vis. Comput. Graph., vol. 23, no. 11, pp. 2372-2377, Nov. 2017.

[18] Z. Chaczko, W. Alenazy, L. Carrion, and A. Tran, "Augmented Reality based monitoring of the remotelab," in Information Technology Based Higher Education and Training (ITHET), 2014, 2014, pp. 1-5.

[19] J. Burke, "Browsing an Augmented Reality with Named Data Networking," presented at the International Conference on Computer Communication and Networks (ICCCN), International Conference on Computer Communication and Networks (ICCCN), 2017.

[20] D. Goldsmith, F. Liarokapis, G. Malone, and J. Kemp, “Augmented Reality Environmental Monitoring Using Wireless Sensor Networks,” 2008, pp. 539-544.

[21] L.-K. Lee, C.-H. Chau, C.-H. Chau, and C.-T. Ng, "Using Augmented Reality to Teach Kindergarten Students English Vocabulary," 2017, pp. 53-57.

[22] H. Hu, X. Gao, H. Sun, Q. Jia, and Y. Zhang, "Design and implementation of the teleoperation platform based on augmented reality," in Cognitive Informatics \& Cognitive Computing (ICCI* CC), 2013 12th IEEE International Conference on, 2013, pp. 126-132. 
[23] S. Pan, B. Liu, L. Zhang, and P. Zhang, "iCEnergy: augmented reality display for intuitive energy monitoring," in Proceedings of the 10th ACM Conference on Embedded Network Sensor Systems, 2012, pp. 381-382.

[24] S. R. Gandhi, "A Real Time Indoor Navigation and Monitoring System for Firefighters and Visually Impaired," 2011. 